\title{
THE TREND OF EPIDEMIOLOGICAL DATA IN PATIENTS WITH LUNG CANCER ADDRESSED TO A ROMANIAN TERTIARY PNEUMOLOGY SERVICE
}

\author{
Bianca PARASCHIV ${ }^{1,2}$, Camelia C. DIACONU ${ }^{1,3} \sqrt{ }$, Alina CUCU ${ }^{4}$, Miron A. BOGDAN ${ }^{1,4}$, \\ Claudia L. TOMA ${ }^{1,4}$ \\ ${ }^{1}$ University of Medicine and Pharmacy "Carol Davila“, Bucharest, Romania \\ 2 „Sfantul Stefan“ Hospital, Bucharest, Romania \\ ${ }^{3}$ Internal Medicine Clinic, Clinical Emergency Hospital of Bucharest, Bucharest, Romania \\ ${ }^{4}$ „Marius Nasta“ National Institute of Pneumology, Bucharest, Romania
}

Received 03 Apr 2019, Accepted 15 May 2019

https://doi.org/10.31688/ABMU.2019.54.2.09

\section{Abstract}

Introduction. The lung cancer has an increased incidence and is associated with the highest death by cancer worldwide. It represents a heterogenous disease with variability in trends and has a severe socio-economical impact. That is why it should be continuously monitored, especially in countries without national registries or screening programs.

The objective of the study was to identify the epidemiological trend in patients with lung cancer addressed to a Romanian tertiary pneumology service.

Material and methods. We performed a retrospective study on 660 patients diagnosed with lung cancer: the first group of 260 patients diagnosed between $2001-2004$, and the second group of 400 patients diagnosed between 2009-2010.

Results. Patients from the first group had a mean age of $61.20 \pm 11.14$ years. $80.80 \%$ of them were men and $80.76 \%$ smokers. The main symptoms were cough (46.92\%) and dyspnea (45\%). The most frequent histological subtype was squamous cell carcinoma

\section{Résumé}

Lévolution des caractéristiques épidémiologiques chez des patients atteints d'un cancer du poumon traités dans un centre roumain de spécialité

Introduction. Le cancer du poumon a une incidence accrue et il est associé au plus grand nombre de décès par cancer dans le monde. Il représente une maladie hétérogène dont les tendances varient et a donc un impact socio-économique grave. C'est pourquoi il devrait être continuellement surveillé, en particulier dans les pays sans programme national de registre ou de dépistage.

L'objectif de l'étude a été d'identifier la tendance épidémiologique chez les patients atteints de cancer du poumon dans notre clinique.

Matériaux et méthodes. Nous avons mené une étude rétrospective sur 660 patients atteints d'un cancer du poumon : un premier groupe de 260 patients diagnostiqués entre 2001-2004 et un second groupe de 400 patients diagnostiqués entre 2009-2010. 
(44.13\%). Only 35 patients from the first group underwent surgery. In 2004, from 260 patients enrolled, 20 were still alive. In the second group the mean age was $63.97 \pm 10.27$ years. $79.05 \%$ were men and $84.29 \%$ smokers. The main symptoms were cough $(58.12 \%)$ and dyspnea (40.10\%). The most frequent histological subtype was the squamous cell carcinoma (47.13\%). Surgery was performed in 65 patients $(16.25 \%)$ and they had mean survival of 50 months.

Conclusions. The incidence of lung cancer is increasing, especially in centers without screening programs. There is no change in male prevalence over the years. Despite the fact that, worldwide, adenocarcinoma has increased incidence, in our study squamous cell carcinoma was the main histological subtype. The delays in diagnosis remain similar. The majority of patients are still diagnosed in advanced stages, when curative treatment cannot be applied.

Keywords: lung cancer, epidemiology, trend, screening.

\author{
Abbreviations list \\ COPD - chronic obstructive pulmonary disease \\ ICD - International Classifications of Diseases \\ NSCLC - non-small cell lung cancer \\ PA - Pack-years \\ SCLC - small cell lung cancer \\ TNM - Tumor-Node-Metastasis \\ WHO - World Health Organisation
}

\section{INTRODUCTION}

Starting from 1840, when there were reported only 22 cases in the past 100 years, the lung cancer has changed from a rare disease into a global prob$1 \mathrm{em}{ }^{1,2}$. In 2018, there were about 18.1 million of new cases, with 9.6 million deaths due to cancer ${ }^{3}$. The lung cancer is associated with the highest incidence of death through cancer worldwide ${ }^{1}$.

The incidence and mortality rates vary widely globally ${ }^{2}$. The lung cancer incidence in countries with a low-medium income represents about 50\% from the total new cases ${ }^{1}$. In Europe, the lung cancer exceeded breast cancer mortality rates for the first time in 20174. The main incidence of lung cancer in Europe was reported in Central and Eastern regions $s^{5}$. The most important risk factor remains tobacco smoking. Other risk factors are: advanced age, race, sex (male), occupational exposure (mainly radon exposure), pre-existing diseases (chronic obstructive pulmonary disease - COPD, tuberculosis), genetic susceptibility (alteration on chromosome: 15q24-15q25.1, 5p15.33, 6p21.33, 13q31.36.8.
Résultats. Dans le premier groupe, nous avons observé un âge moyen de $61,20 \pm 11,14$ ans, une incidence élevée chez les hommes $(80,80 \%)$, dont $(80,76 \%)$ des fumeurs, présentant les principaux symptômes: toux $(46,92 \%)$ et dyspnée (45\%) et stade avancé de la MNT. Le sous-type histologique principal était le carcinome à cellules squameuses (44,13\%). Seulement 35 patients ont été opérés. En 2004, sur 260 patients inscrits, 20 étaient encore en vie. Dans le deuxième groupe, nous avons signalé un âge moyen de 63,97 $\pm 10,27$ ans, avec également une incidence élevée chez les hommes $(79,05 \%)$, des fumeurs $(84,29 \%)$, présentant les principaux symptômes: toux $(58,12 \%)$ et dyspnée $(40,10 \%)$ et stade avancé de TNM. Le sous-type histologique principal était le carcinome à cellules squameuses (47,13\%). La chirurgie a été réalisée chez 65 patients $(16,25 \%)$ et leur survie moyenne était de 50 mois.

Conclusions. L'incidence du cancer du poumon augmente, en particulier dans les centres sans programme de dépistage ni accès à un traitement moléculaire. La prévalence masculine n’a pas changé au fil des années. En dépit du fait que l'adénocarcinome a augmenté d'incidence dans le monde, dans notre étude, le carcinome à cellules squameuses reste le principal sous-type histologique. Le délai du diagnostic reste similaire. La majorité des patients est encore diagnostiquée à un stade avancé en l'absence d'un traitement radical.

Mots-clés: cancer du poumon, épidémiologie, tendance, screening.

Lung cancer represents a heterogenous disease, with variability in trends, and has a severe socio-economical impact. The identification of epidemiological features in one region may bring benefits in survival, by adapting screening programs and treatment ${ }^{9}$. That is why lung cancer should be continuously monitored for epidemiological trends, especially in countries without national registries or implemented screening programs.

The objective of the study was to identify the changes in epidemiological features over more than a decade in patients with lung cancer treated in our clinic.

\section{Material AND Methods}

We performed a retrospective study on 660 patients diagnosed in the $4^{\text {th }}$ Department of the "Marius Nasta" National Institute of Pneumology, Bucharest, Romania with lung cancer, defined as ICD 10 codes C34. The patients were divided in two groups: the first group of 260 patients diagnosed 
between 2001-2004, and the second group of $400 \mathrm{pa}$ tients diagnosed between 2009-2010.

The information was obtained from the medical files of the patients found in the hospital archive. We included all the patients diagnosed with lung cancer. The access to the observation sheets was done based on a previous permission granted by the hospital management. On admission, each patient consented that his medical information may be used for research purposes.

The statistical interpretation of data included a descriptive analysis carried out in the form of Medium \pm Standard Deviation (SD) and minimum and maximum for the continuous variables, and in the form of absolute frequencies (number) and relative frequencies (percentage) for the category variables; the survival was investigated with Kaplan-Meyer analysis.

\section{Results}

The statistical analysis was performed for each group individually. The results were compared and discussed for each variable separately.

The first group of patients included 260 subjects. We observed a constant increase in the incidence of lung cancer over the years (Figure 1). The general characteristics of the group are resumed in Table 1 . About $56 \%$ of the patients accused symptoms with at least 2 months before presentation for medical examination. The main clinical features were cough $(46.92 \%)$ and dyspnea $(45 \%)$. Only $6 \%$ of patients were asymptomatic and diagnosed on a routinely performed chest X-ray (Table 2). The mean age at the time of diagnosis was around 60 years old, with $33 \%$ of patients aged between $55-64$ years old. The

Table 1. General characteristics of the groups of study.

\begin{tabular}{lccc}
\hline Variable & & Group 1 & Group 2 \\
\hline Age - Average \pm D.S & & $61.20 \pm 11.14$ & $63.97 \pm 10.27$ \\
\hline \multirow{2}{*}{ Sex } & M & $209(80.08 \%)$ & $317(79.05 \%)$ \\
& F & $51(19.92 \%)$ & $84(20.95 \%)$ \\
\multirow{2}{*}{ Smokers } & Yes & $210(80.76 \%)$ & $338(84.29 \%)$ \\
& No & $50(19.23 \%)$ & $63(15.71 \%)$ \\
\multirow{2}{*}{ TNM stage } & 1 & $10(4.03 \%)$ & $19(5.29 \%)$ \\
& 2 & $16(6.15 \%)$ & $22(6.13 \%)$ \\
& 3 & $98(37.69 \%)$ & $124(34.54 \%)$ \\
\multirow{4}{*}{ Histology } & 4 & $136(52.13 \%)$ & $194(54.04 \%)$ \\
& Squamous & $109(44.13 \%)$ & $123(47.13 \%)$ \\
& ADK & $91(36.84 \%)$ & $98(37.55 \%)$ \\
& Others & $18(7.29 \%)$ & $6(2.30 \%)$ \\
\end{tabular}

\section{Incidence of lung cancer 2001-2004 in our clinic}

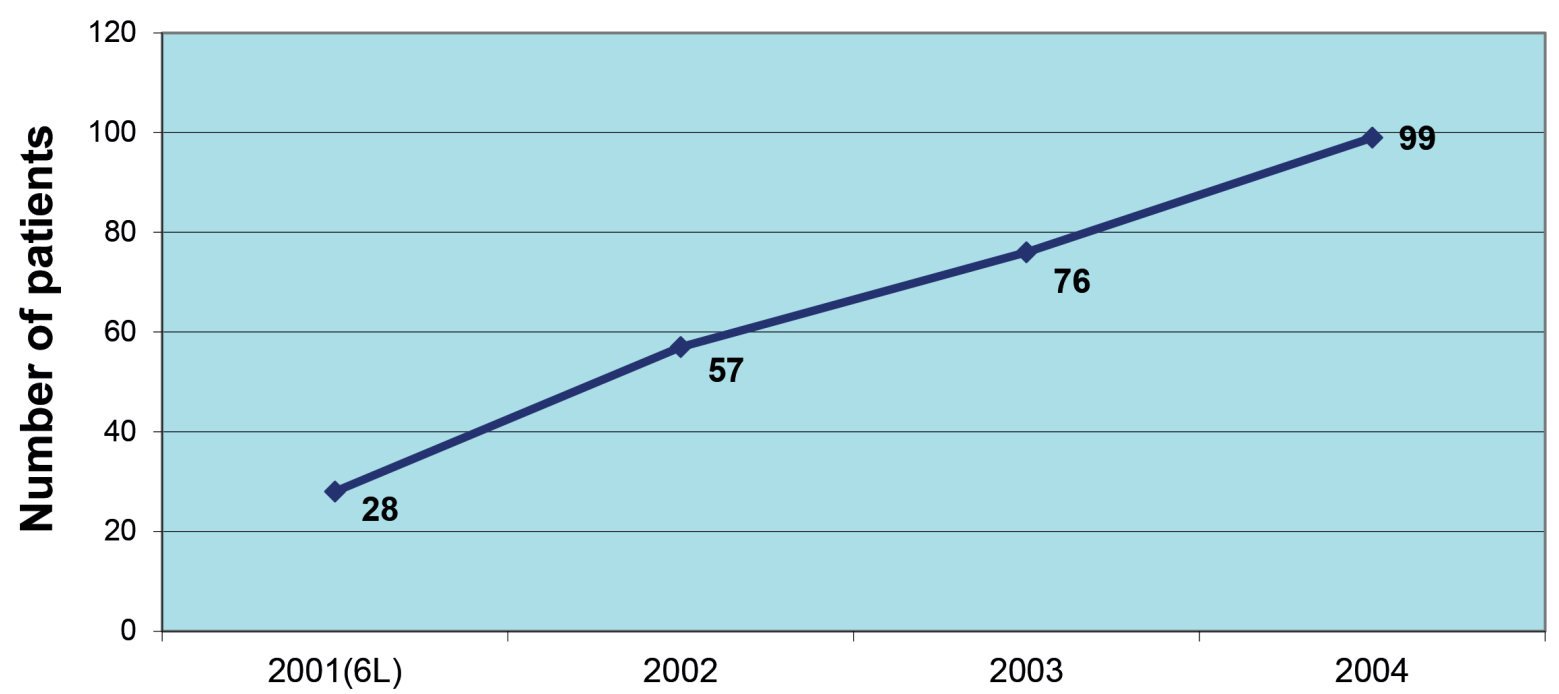

Figure 1. The increasing incidence of lung cancer in our clinic between 2001-2004. 
Table 2. Clinical features of the groups of study

\begin{tabular}{lccc}
\hline Variable & & Group 1 & Group 2 \\
\multirow{2}{*}{ Asymptomatic $(\mathrm{N}=249)$} & Yes & $15(5.77 \%)$ & $25(10.04 \%)$ \\
\hline \multirow{2}{*}{ Dyspnea } & No & $245(94.23 \%)$ & $224(89.96 \%)$ \\
\hline \multirow{2}{*}{ Cough } & Yes & $117(45 \%)$ & $158(40.10 \%)$ \\
& No & $143(55 \%)$ & $236(59.90 \%)$ \\
\hline \multirow{2}{*}{ Fatigue } & Yes & $122(46.92 \%)$ & $229(58.12 \%)$ \\
& No & $138(53.08 \%)$ & $165(41.88 \%)$ \\
\multirow{2}{*}{ Chest paint } & Yes & $65(25 \%)$ & $120(30.53 \%)$ \\
\multirow{2}{*}{ Hemoptysis } & No & $195(75 \%)$ & $273(69.47 \%)$ \\
\hline \multirow{2}{*}{ Dysphonia } & Yes & $70(26.92 \%)$ & $128(32.57 \%)$ \\
& No & $190(70.08 \%)$ & $265(67.43 \%)$ \\
\multirow{2}{*}{ Dysphagia } & Yes & $75(28.85 \%)$ & $92(23.41 \%)$ \\
& No & $185(71.15 \%)$ & $18(4.58 \%)$ \\
\multirow{2}{*}{ Superior Vena } & Yes & $14(5.39 \%)$ & $375(95.42 \%)$ \\
\hline
\end{tabular}

Kaplan-Meyer-general survival

Strata + All
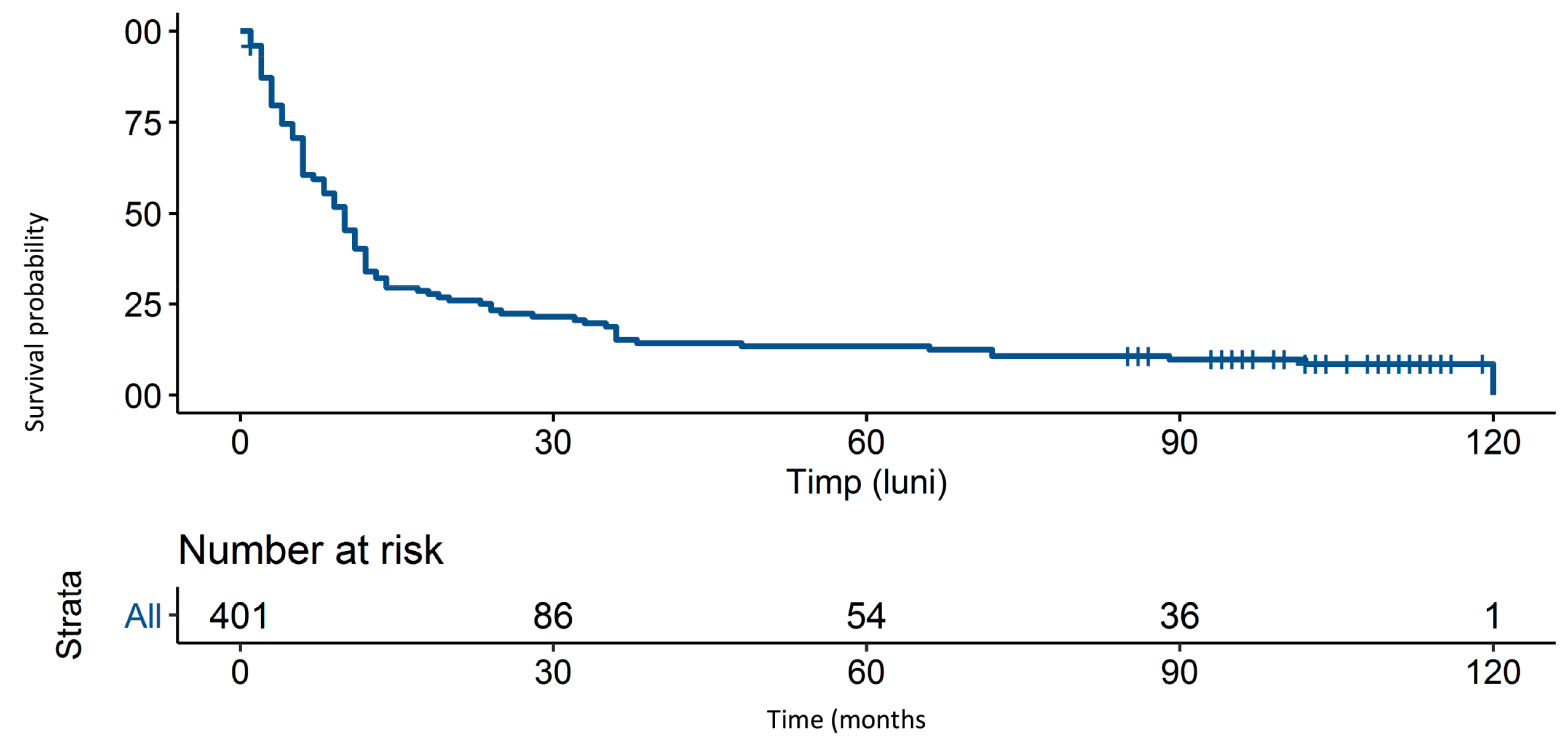

Figure 2. The general survival in the second group of study.

majority of patients were male $(80.80 \%)$ and heavy smokers $(80.76 \%)$. The main comorbidities were cardiovascular diseases (12\%) and chronic obstructive pulmonary disease (13\%). The main histological subtype was squamous cell carcinoma (44.13\%). Most patients presented with advanced disease: $89.91 \%$ in stage III and IV. Treatment with intent to cure was proposed to 50 patients, but only 35 patients underwent surgery: 8 patients with stage I, 10 patients with stage II, 11 patients in stage III A, 2 patients in stage IIIB, 4 patients in stage IV (patients with unique metastases and resectable primary tumor). The types of surgery excisions were: lobectomy (the most frequent), bi-lobectomy, pneumectomy. None of these 35 patients underwent neo-adjuvant chemotherapy. In 2004, from 260 patients enrolled, 20 were still alive. From those 20 patients, 15 benefited from surgical treatment. 
In the second group, there were included 400 patients, with a mean age of approx. 60 years old also. The main features are presented in Table 1 . We observed a male prevalence (79.05\%). The majority of patients were smokers $(84.29 \%)$ with an average packs-year of $42.86 \pm 20.25$. Only $21.30 \%$ of them had professional exposure. About $5.99 \%$ of patients had a family history of lung cancer. The main comorbidities were cardiovascular diseases. The most prevalent clinical features were cough $(58.12 \%)$ and dyspnea $(40.10 \%)$. The main histological type was the non-small cell lung cancer (NSCLC), represented mainly by squamous cell carcinoma $(47.13 \%)$ and adenocarcinoma (37.55\%). Approximately $88.58 \%$ of patients were diagnosed in advanced stages. Surgery was performed in 65 patients $(16.25 \%)$. The main techniques were lobectomy and wedge resection. In the group of patients who underwent surgery, the prognosis was better: they had a mean survival of 50 months vs. a mean survival of approximately 17 months in patients in whom the radical surgery was not possible $(\mathrm{p}<0.01)$. Most patients were treated with chemotherapy in an external oncology service. In patients who were not candidates for surgical procedures and were treated with chemotherapy the mean survival was 6 months longer in the group with chemotherapy.

\section{Discussion}

Only about one sixth of the countries worldwide have cancer registries ${ }^{10}$. In Romania, there is not a national registry of lung cancer. One of the purposes of these registries is to identify the risk factors based on epidemiological features for each geographic region, in order to implement custom made screening programs. Given that survival in lung cancer dramatically decreases with disease progression, the early diagnosis remains essential ${ }^{11}$. That is why the screening programs play a key-role in survival. In Europe, the screening is performed yearly by low-dose computed tomography scans in patients at risk (55-80 years old, smokers or ex-smokers secluded for a maximum of 15 years, with a history of at least $30 \mathrm{PA}$, with one additional risk factor - personal history of cancer/ COPD/ pulmonary fibrosis/ occupational exposure or family history of lung cancer) only in specialized medical centers ${ }^{12}$. In Romania, there are no screening programs implemented, so all the data regarding lung cancer come from different studies performed in several clinics.

The first variable analyzed was the evolution of incidence over the years. Our data confirm that there is a significant increase of lung cases reports since 2001 until 2010. The results confirm the reports published, according to which the global incidence of cancer is constantly increasing ${ }^{1}$.

Age was a frequent analyzed feature. Some studies stipulated that an advanced age (over 65 yo in some reports, or over 70 yo) is associated with a worse prognosis, but other studies did not confirm $\mathrm{it}^{13}$. Nevertheless, most cases of lung cancer are diagnosed in patients between 55-74 years old, that is why it is difficult to establish the age impact on survival ${ }^{2}$. In our study, we encountered a mean age of about 60 years old in both groups $(61.20 \pm 11.14$ vs $63.97 \pm 10.27)$. We observed that over a decade there was no significant change of this parameter. Our results confirm the ones published in other studies.

In the last years, many epidemiological studies observed a decrease in the incidence among men and an increase among women ${ }^{2}$. The highest incidence in women was reported in North America and Northern Europe $^{10}$. These changes may be influenced also by smoking habits and by genetic alteration, such as over-expression of the CYP1A1 gene or of X-linked gastrin-releasing peptide receptor and mutation of the glutathione S-transferase M1 enzyme or of the p53 tumor suppressor gene ${ }^{(14)}$. Nevertheless, the incidence in men remains higher than in women ${ }^{1}$. In our study, we observed the same results: a high incidence in male, which was preserved over the years: $209(80.08 \%)$ vs 317 (79.05\%).

Some researchers have argued that the African race is a negative prognostic factor ${ }^{15}$. However, after adjusting the results with socio-cultural differences (access to medical services, smoker status, diet, sedentary lifestyle), the influence of race on the evolution of lung cancer fades away, ${ }^{2,16}$. In our group, we could not assess race differences because all patients were Caucasians.

Smoking as risk factor for lung cancer has been recognized since 1960 . About $80 \%$ of lung cancers are linked to tobacco smoking ${ }^{6}$. Both the duration and the number of cigarettes per day are independent risk factors. Knowing the high incidence of smoking between lung cancer patients, an active and constant fight for its cessation can make the difference. For example, in the USA, the age-adjusted incidence has declined due to changes in risk behaviors secondary to promulgation of information about the main risk factor: tobacco smoking ${ }^{2}$. In our country, only a few years ago a law prohibiting smoking in closed spaces was promulgated, so smoking remains a main risk factor for the population included in our study. There are no differences between smoking incidence over the years: $210(80.76 \%)$ vs 338 ( $84.29 \%)$. The high incidence of tobacco use correlates with the results reported by other studies.

In 2015, the World Health Organization (WHO) published the latest histopathological classification 
based on immunohistochemistry and genetics tests and on the degree of differentiation. The NSCLC type has been reported to have the highest prevalence ${ }^{17}$. Recent studies suggest an increase in the incidence of adenocarcinoma at the expense of squamous carcinoma $^{18,19}$. We also identified in our group a prevalence of NSCLC constant over the years: 80.97 vs $84.68 \%$. However, we did not observe an increase of incidence of adenocarcinoma. In both groups, squamous cell carcinoma had a higher prevalence: $44.13 \%$ vs $47.13 \%$. Furthermore, studies reported a higher incidence of adenocarcinoma in male patients ${ }^{2}$. Even though in our study there was a male predominance, squamous cell carcinoma remains the most frequent histological subtype over the years.

The TNM classification was first described in 1942-1952 in France and in 1958 there were published the first guidelines. It applies in SCLC and NSCLC, including the carcinoid tumors, but not for rare tumors, such as sarcoma. The TNM classification is repeatedly identified as an essential prognostic factor in the progression of lung cancer. In 2017, the eighth edition of TNM staging was used ${ }^{20}$. However, the classification of the patients in our study was based on the staging valid at the time of diagnosis. Despite the TNM edition used, the reports have shown that the diagnosis is confirmed mainly in advanced stages: only $15 \%$ of cases are diagnosed in early stages ${ }^{21}$. The same results we observed in our study, where despite a decade of progress the majority of patients are still diagnosed in advanced stages, when curative therapy is no longer an option: $89.91 \%$ vs $88.58 \%$.

With the progress of surgical procedures and discovery of molecular treatment, the survival rate has increased over the years, but lung cancer is still associated with highest mortality. The 1-year relative survival rate increased from 35\% in 1975-1979 to $42 \%$ in $1988-2008^{21}$. The prognosis is influenced by many factors: patients' characteristics (clinical status, comorbidities, age) and tumor characteristics (TNM stage, histopathology, immunohistochemistry $)^{22}$. From all these factors, the TNM classification has an important role: the survival rate decreases from stage I (where is estimated at 59 months) to 4 months in stage IV ${ }^{23}$. These observations are sustained by the results of our study. In both groups, the survival was better in early TNM stages, where surgical resection was performed.

\section{LIMITATIONS OF THE STUDY}

Our research presents some limitations of statistical analysis, mainly because a retrospective study is a source of recall bias. Other limitation come from the incomplete data from the patients' charts, due to the lack of national registries.

\section{Conclusions}

Lung cancer is associated with a high mortality. The prevalence is increasing from few cases in 2001 to nearly a hundred new cases in 2009. The mean age at diagnosis remains around $60 \mathrm{yo}^{24}$. There is still a male predominant distribution. Smoking incidence is high in our groups, without significant decrease over the years as it was reported in other countries. Squamous cell carcinoma remains the predominant histopathological subtype over the years. Similar delay between symptoms and diagnosis is observed in both groups. The main clinical symptoms remain dyspnea and cough. Patients continue to be diagnosed in advanced stages ${ }^{25}$. Treatment with the intent to cure has a significant benefit for survival.

Lung cancer remains a global burden because of the aggressive character of the disease and its constantly increasing incidence. Primary prevention, such as tobacco control, remains a key factor in prognosis improvement. Understanding the evolution of epidemiological features in lung cancer provides the necessary information for screening programs to be tailored to populations at highest risk. The implementation of screening programs and national registries is essential for improving the survival rate.

\section{Compliance with Ethics Requirements:}

„The authors declare no conflict of interest regarding this article"

"The authors declare that all the procedures and experiments of this study respect the ethical standards in the Helsinki Declaration of 1975, as revised in 2008(5), as well as the national law. Informed consent was obtained from all the patients included in the study"

"No funding for this study"

\section{References}

1. www.globocan.iac.fr. (accesed 12 March 2019).

2. de Groot PM, Wu CC, Carter BW, Munden RF. The epidemiology of lung cancer. Transl Lung Cancer Res. 2018;7(3):220-233.

3. World Health Organization. Press release no 263, 12 Septembrie 2018. Globocan database. https://www.who. int/cancer/PRGlobocanFinal.pdf. (Accessed 01 April 2019).

4. Malvezzi M, Carioli G, Bertuccio P, et al. European cancer mortality predictions for the year 2017, with focus on lung cancer. Ann Oncol. 2017;28(5):1117-1123.

5. Siegel R, Naishadham D, Jemal A. Cancer statistics. CA Cancer J Clin. 2012;62 (1):10-29.

6. Malhotra J, Malvezzi M, Negri E. Risk factors for lung cancer worldwide. Eur Respir J. 2016; 48(3):889-902.

7. Spyratos D, Zarogoulidis P, Porpodis K, et al. Occupational exposure and lung cancer. J Thorac Dis. 2013;5(4):S440S445. 
8. Pallis AG, Syrigos KN. Lung cancer in never smokers: disease characteristics and risk factors. Crit Rev Oncol Hematol. 2013; 88(3):494-503.

9. Gaga M, Powell CA, Schraufnage DE, et al. An official American Thoracic Society/ European Respiratory Society statement: the role of the pulmonologist in the diagnosis and management of lung cancer. Am J Respir Crit Care Med. 2013;188(4):503-507.

10. Cheng T-YD, Cramb SM, Baade PD. The international epidemiology of lung cancer: latest trends, disparities, and tumor characteristics. J Thorac Oncol. 2016;11(10):1653-1671.

11. Field JK, Chen Y, Marcus MW, et al. The contribution of risk prediction models to early detection of lung cancer. J Surg Oncol. 2013;108 (5):304-311.

12. Kauczor H-U., Bonomo L, Gaga M, et al. ESR/ERS white paper on lung cancer screening. Eur Respir J. 2015;46 (1):28 39.

13. Carter GC, Barrett AM, Kaye JA, et al. A comprehensive review of nongenetic prognostic and predictive factors influencing the heterogeneity of outcomes in advanced non-small-cell lung cancer. Cancer Management and Research. 2014:6:437-449.

14. Kligerman S, White C. Epidemiology of lung cancer in women: risk factors, survival, and screening. AJR Am J Roentgenol. 2011;196 (2):287-95

15. Blackstock AW, Herndon JE 2nd, Paskett ED, et al. Outcomes among African-American/non African-American patients with advanced non-small cell lung carcinoma: report from the Cancer and Leukemia Group B. J Natl Cancer Inst. 2002;94:284
16. Patel MI, Wang A, Kapphahn K, et al. Racial and ethnic variations in lung cancer incidence and mortality: results from the women's health initiative. Clin Oncol. 2016;34 (4):360-368.

17. Travis D, Brambilla E, Nicholson AG, et al. The 2015 World Health Organization classification of lung tumors: Impact of Genteic, Clincal and Radiologic Advances Since the 2004 Classification. J Thorac Oncol. 2015;10(9):1243-1260.

18. Dela Cruz CS, Tanoue LT, Matthay RA. Lung cancer: epidemiology, etiology, and prevention. Clin Chest Med. 2011; 32(4):605-644.

19. Paraschiv B, Dediu G, Iancu A, Bratu O, Diaconu C. Superior vena cava syndrome - review. Arch Balk Med Union 2017;52(1):39-43.

20. Detterbeck FC, Boffa DJ, Kim AW, et al. The eighth edition lung cancer stage classification. Chest. 2017;151(1):193-203.

21. Ridge CA, McErlean AM, Ginsberg MS. Epidemiology of lung cancer. Semin Intervent Radiol 2013;30 (2):93-98.

22. Ciuhu AN, Rahnea Nita RA, Popescu M, et al. Evidence of strong opioid therapy for palliation of breathlesness in cancer patients. Farmacia 2017;65(2):173-178.

23. Midthun DE. Overview of the initial evaluation, treatment and prognosis of lung cancer. www.uptodate. (Accessed August 2018).

24. Diaconu CC, Arsene D, Paraschiv B, Balaceanu A, Bartos D. Hyponatremic encephalopathy as the initial sign of neuroendocrine small cell carcinoma - case report. Acta Endocrinologica 2013;IX(4): 637-642.

25. Paraschiv B, Diaconu C, Toma C, Bogdan M. Paraneoplastic syndromes: the way to an early diagnosis of lung cancer. Pneumologia 2015;64(2):14-19. 